\title{
ASPETTI FARMACOLOGICI E VIROLOGICI DI UNA COORTE DI PAZIENTI IN TERAPIA ANTIRETROVIRALE CONTENENTE EFAVIRENZ.
}

Faraoni S., Gregori G., Di Garbo A., Ghiotti M., Morettini R., *Gonzalez de Requena D., *Bonora S., Milia M.G.

Dipartimento di Diagnostica di Laboratorio

- Laboratorio di Biologia Molecolare.

Ospedale Amedeo di Savoia, Torino.

*Dipartimento di Malattie Infettive, Università di Torino

Introduzione. La concentrazione dell'HIV1-RNA nel plasma è un'importante fattore predittivo nell'evoluzione dell'infezione ed un marker dell'efficacia della terapia antiretrovirale. Anche quando la viremia è al di sotto della soglia di rilevabilità ( 50 copie $/ \mathrm{ml})$, il virus mantiene un certo livello di replicazione ed è in grado di sviluppare farmacoresistenze. Obiettivo dello studio è stata la valutazione dell'incidenza della soppressione virologica al di sotto delle 3 $\mathrm{copie} / \mathrm{ml}$ sia in fase precoce che in fase avanzata di successo virologico di terapie antiretrovirali basate su efavirenz, analizzando i possibili determinanti fattori clinici, demografici e farmacocinetici.

Metodi. Sono stati analizzati 65 pazienti in terapia antiretrovirale contenente efavirenz, tutti con carica virale inferiore alle $50 \mathrm{copie} / \mathrm{ml}$. Di ciascuno è stata considerato il primo campione con HIV-RNA inferiore alle $50 \mathrm{copie} / \mathrm{ml}$ ed il successivo a 12 mesi di distanza. L'analisi di quantizzazione è stata eseguita mediante una variazione della metodica "ultrasensibile" HIV Monitor di Roche (cut off 3 copie $/ \mathrm{mL}$ ).

Risultati. Un valore di viremia al di sotto delle 3 copie $/ \mathrm{ml} \mathrm{si}$ è osservato in circa $50 \%$ dei pazienti in occasione della prima determinazione. Tale valore non è risultato associato né allo status di naive né alla presenza di soppressione della carica virale al baseline. Una carica virale sotto le 3 copie alla prima soppressione è risultata associarsi significativamente al mantenimento della stessa a 12 mesi di soppressione. Le concentrazioni di efavirenz a 12 mesi di soppressione, sono significativamente superiori nei pazienti che presentano una viremia plasmatica inferiore a 3 copie $/ \mathrm{ml}$ rispetto a chi ha un livello di HIV-RNA $>3$ copie $/ \mathrm{ml}$.

Conclusioni. Il mantenimento di una concentrazione di farmaco ai limiti inferiori del range di normalità potrebbe determinare il parallelo mantenimento di una viremia compresa tra le 3 e le 50 copie/ml, determinando un tasso di replicazione virale limitato ma sufficiente a selezionare mutanti resistenti ad efavirenz. 